\title{
Conformational and Translational-Rotational Entropy from Molecular Ensembles ${ }^{\dagger}$
}

\author{
Federico Fogolari \\ University of Udine, Udine, Italy \\ + Presented at the Entropy 2021: The Scientific Tool of the 21st Century, 5-7 May 2021; Available online: \\ https://sciforum.net/conference/Entropy2021/.
}

Published: 5 May 2021

Entropy calculation is an important step in the postprocessing of molecular dynamics trajectories or predictive models. In recent years the nearest neighbor method proposed by Demchuk and coworkers [1] has emerged as a powerful method to deal in a flexible way with the dimensionality of the problem. Applications to most important biomolecular processes have been presented [2,3] and a specific development has concerned the computation of rotational-translational entropy which required in turn the definition of a metric in rotation-translation space [4]. Two programs have been developed to compute conformational and rotational-translational entropies from biomolecular ensembles [5]. Possible estensions of the method will be presented.

\section{References}

1. Singh, H.; Misra, N.; Hnizdo, V.; Fedorowicz, A.; Demchuk, E. Nearest neighbor estimates of entropy. Am. J. Math. Manag. Sci. 2003, 23, 301-321.

2. Fogolari, F.; Corazza, A.; Esposito, G. Free energy, enthalpy and entropy from implicit solvent end-point simulations. Front. Mol. Biosci. 2018, 5, 11.

3. Fogolari, F.; Corazza, A.; Fortuna, S.; Soler, M.A.; VanSchouwen, B.; Brancolini, G.; Corni, S.; Melacini, G.; Esposito, G. Distance-based configurational entropy of proteins from molecular dynamics simulations. PLoS ONE 2015, 10, e0132356.

4. Fogolari, F.; Foumthuim, C.J.D.; Fortuna, S.; Soler, M.A.; Corazza, A.; Esposito, G. Accurate Estimation of the Entropy of Rotation-Translation Probability Distributions. J. Chem. Theory Comput. 2016, 12, 1-8.

5. Fogolari, F.; Maloku, O.; Foumthuim, C.J.D.; Corazza, A.; Esposito, G. PDB2ENTROPY and PDB2TRENT: Conformational and Translational-Rotational Entropy from Molecular Ensembles. J. Chem. Inf. Model. 2018, $58,1319-1324$.

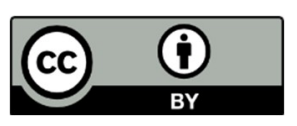

(C) 2021 by the author. Licensee MDPI, Basel, Switzerland. This article is an open access article distributed under the terms and conditions of the Creative Commons Attribution (CC BY) license (http://creativecommons.org/licenses/by/4.0/). 